
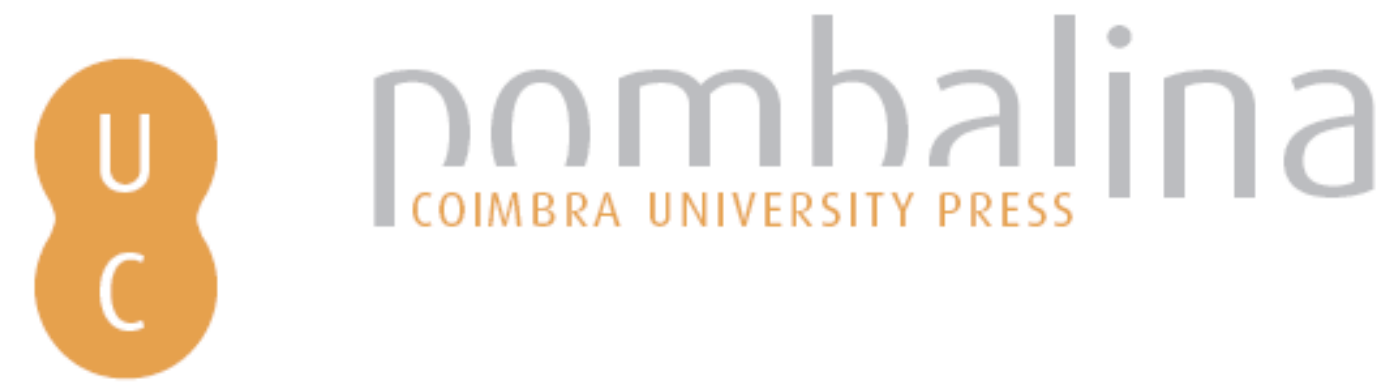

\title{
A lei da mesa. As praxes da etiqueta e as boas maneiras na sociedade de bomtom: algumas fontes para o seu estudo (século XIXprincípios do século XX)
}
Autor(es):
Vaquinhas, Irene
Publicado por: Imprensa da Universidade de Coimbra
URL
persistente:
URI:http://hdl.handle.net/10316.2/43688
DOI:
DOI:https://doi.org/10.14195/978-989-26-1364-2_3
Accessed : $\quad$ 26-Apr-2023 10:47:14

A navegação consulta e descarregamento dos títulos inseridos nas Bibliotecas Digitais UC Digitalis, UC Pombalina e UC Impactum, pressupõem a aceitação plena e sem reservas dos Termos e Condições de Uso destas Bibliotecas Digitais, disponíveis em https://digitalis.uc.pt/pt-pt/termos.

Conforme exposto nos referidos Termos e Condições de Uso, o descarregamento de títulos de acesso restrito requer uma licença válida de autorização devendo o utilizador aceder ao(s) documento(s) a partir de um endereço de IP da instituição detentora da supramencionada licença.

Ao utilizador é apenas permitido o descarregamento para uso pessoal, pelo que o emprego do(s) título(s) descarregado(s) para outro fim, designadamente comercial, carece de autorização do respetivo autor ou editor da obra.

Na medida em que todas as obras da UC Digitalis se encontram protegidas pelo Código do Direito de Autor e Direitos Conexos e demais legislação aplicável, toda a cópia, parcial ou total, deste documento, nos casos em que é legalmente admitida, deverá conter ou fazer-se acompanhar por este aviso.

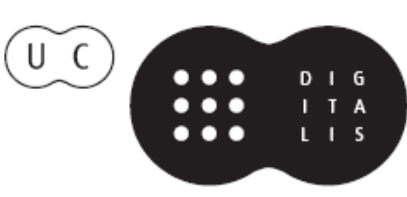




\section{BIBLIOALIMENTARIA}

Alimentação, Saúde e Sociabilidade à Mesa no acervo bibliográfico da Universidade de Coimbra

Carmen Soares (Coord.)
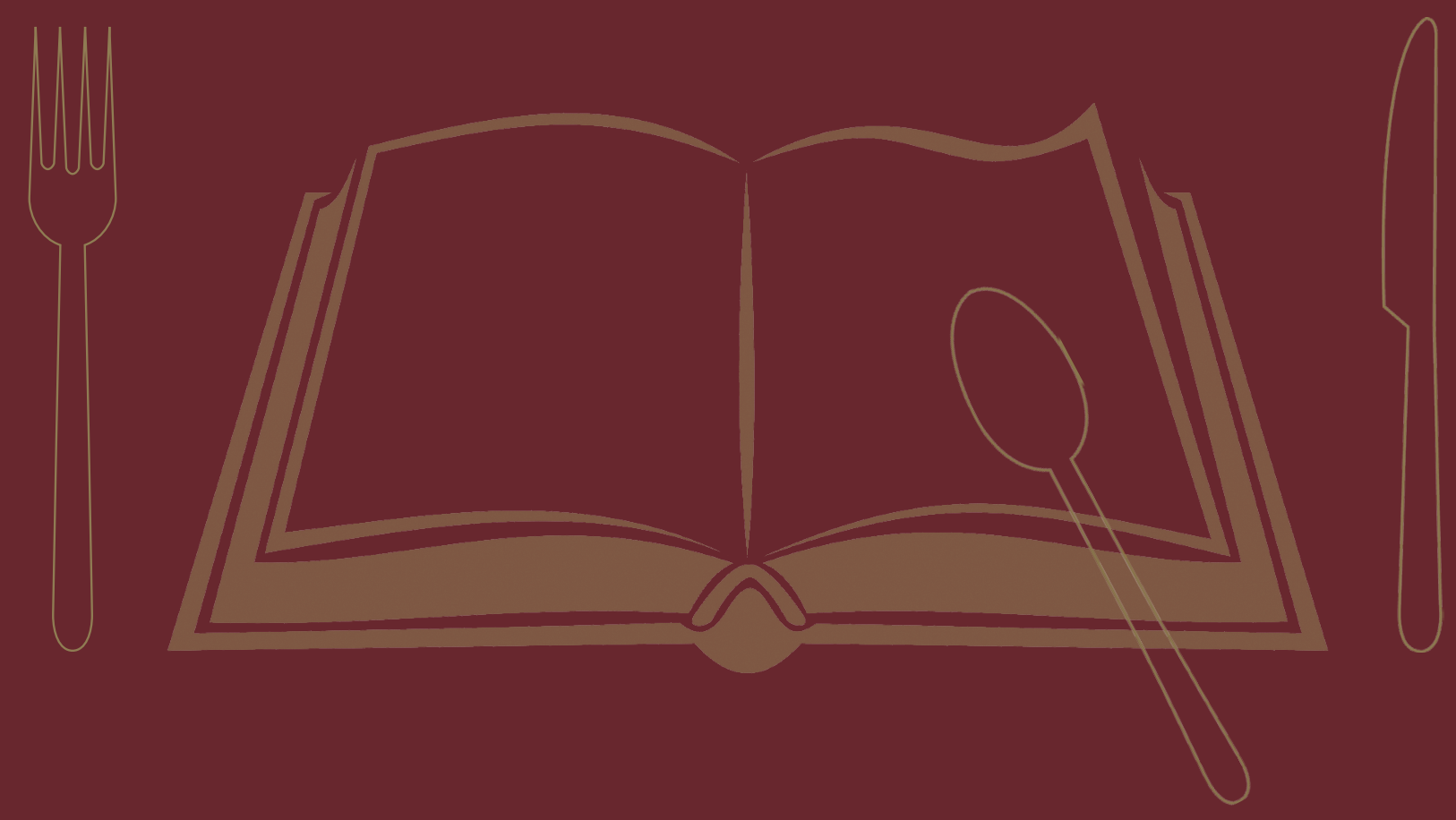

Imprensa da Universidade de Coimbra

Coimbra University Press 
PAC, a agricultura portuguesa e a CEE, a sociologia agrária ou a agricultura na TV, mostrando-se em contínua atualização ${ }^{133}$.

O último número que a Biblioteca Geral da Universidade de Coimbra possui da Gazeta das Aldeias diz respeito ao ano de $2000^{134}$ e nele surgem notícias sobre a Ovibeja, o termo da época de caça em fevereiro, a seca desse ano, o programa de ajudas à agricultura familiar, as leis das abelhas, o crescimento do mercado português de agroquímicos, a qualidade do azeite, a PAC, um colóquio-demonstração na Universidade de Évora, entre outras, e artigos mais informativos sobre as zonas vulneráveis e as boas práticas agrícolas, uma experiência vivida no Alentejo (herbicidas), a cultura do tomateiro, as bananas e as bananeiras, a bolbicultura no século XXI e ainda o problema das moscas em explorações de vacas leiteiras.

Um periódico como a Gazeta das Aldeias, que dura mais de um século, é um monumento, é uma memória escrita perene do passado de um país, a desafiar os historiadores ao seu estudo profundo, iluminando as múltiplas vertentes da agricultura e da produção alimentar, as quais em si mesmas são reflexo e se projetam na política, na economia, na sociedade e nas ideologias de uma Nação e de um Estado.

\section{A lei da mesa. As praxes da etiqueta e as boas maneiras} na sociedade de bom-tom: algumas fontes para o seu estudo (sécullo XIX-princípios do sécullo $\mathbf{x x}$ )

Irene Vaquinbas
133 Gazeta das Aldeias, ano 97 (1992), ns. 2990-3001.

134 Gazeta das Aldeias. Revista Centenária do Mundo Rural, ano 104, n. 3084, janeiro, fevereiro, março 2000.
Os preceitos enunciados foram retirados de manuais de civilidade editados em Portugal, no último quartel do século Xıx e inícios do século xx, correspondendo a traduções de manuais franceses ou a cópias atualizadas de anteriores edições portuguesas. Género literário de cunho pedagógico e moral, este tipo de manual tinha como principais destinatários jovens em idade escolar que frequentavam estabelecimentos de ensino. É o caso, entre outros que se poderiam referir, do Real Colégio Ursulino das Chagas de Cristo, de Coimbra, reservado a meninas das elites, cuja aprendizagem, em termos de civilidade, se norteava pelos ensinamentos prestados por Monsenhor Prevost nos seus Elementos de Civilidade e da decencia que se practica entre gente de bem (cat. n. ${ }^{\circ}$ 93), obra publicada em 1788, na qual reservava um capítulo ao "que 
devemos observar quando estivermos á mesa". Neste campo específico, as regras prescritas pautavam-se por uma clara intenção disciplinadora das funções naturais, pressupondo o cumprimento de interditos, fundamentados no autocontrolo, em alguns aspetos mais pesados para as raparigas do que para os rapazes, para quem funcionavam com um verdadeiro "espartilho ideológico". "Não desdobraremos o guardanapo", "não apresentaremos primeiro o nosso prato para sermos servidos", "não comeremos apressada, e golozamente", "não inclinaremos o corpo sobre o prato", "não abocanharemos o pão", "não chuparemos os ossos para lhe tirar a medula, ou tutano" são algumas das regras apontadas e que exigiam, à mesa, um controle apertado dos gestos e das palavras.

A partir de meados do século XIX, o público destinatário deste tipo de obras alargar-se-á significativamente, incorporando adultos de idade indiscriminada, pertencentes, na sua maioria, à nova burguesia em ascensão, promovida pelo regime liberal e, sobretudo, pelo desenvolvimento económico proporcionado pela Regeneração (1851-1868).

Identificada com uma espécie de "gramática" fornecedora de "um léxico do saber ser e do saber estar em sociedade" (Terra, 2000: 11; 15), a literatura de civilidade tinha o objetivo prático de prestar orientações sobre os comportamentos sociais adequados a cada situação de acordo com o estatuto, o género e o grupo etário, servindo ainda de guia sobre as marcas da distinção no que respeita à postura corporal, atitudes, formas de vestir, de falar ou de comer, tanto em espaços públicos como privados.

O modelo referencial das condutas a adotar tinha por base a pauta de valores das classes dominantes e que se fundamentava na "cortesia", nas "boas maneiras", no "comedimento" e na "polidez". Obedecia, por conseguinte, a princípios socialmente discriminatórios, tendo como contra-modelo os comportamentos das classes populares, considerados "vulgares" e destituídos de "educação", ou, como referia Roquette, "grossarias que cheiram a miséria e a má criação" (Roquette, 1850: 93). Pelas suas intenções aristocratizantes e de "produção da diferença" (Santos, 1983: 23), os manuais de civilidade contribuíram para assegurar à burguesia recém-nobilitada "o prestígio e o luzimento" que a capacidade económica só por si era insuficiente para fazer (Vaquinhas, Cascão, 1993: 449-452). Facilitando o processo de apropriação do capital simbólico da nobreza, desempenharam um importante papel na "legitimação da nova classe que ascende ao poder" (Santos, 1977: 17; Rasteiro, 2010: 22-24).

Sendo obras de grande divulgação, integrando-se em coleções populares, alguns manuais alcançaram grande sucesso editorial no nosso país, sucedendo-se as reedições ano após ano. Sem qualquer pretensão de exaustividade, saliente-se, de entre os manuais mais difundidos, o Codigo do bom tom ou regras da civilidade e de bem viver no XIX século, do cónego J. L. Roquette (cat. n. ${ }^{\circ}$ 94), cuja $1^{\text {a }}$ edição data de 1850 , tendo também sido adaptado ao Brasil (Santana, 2014), ou o Codigo de Civilidade e Costumes do bom-tom seguido do Codigo Heraldico, de Henrique Zeferino, publicado em 1894 (cat. n. ${ }^{\circ}$ 95).
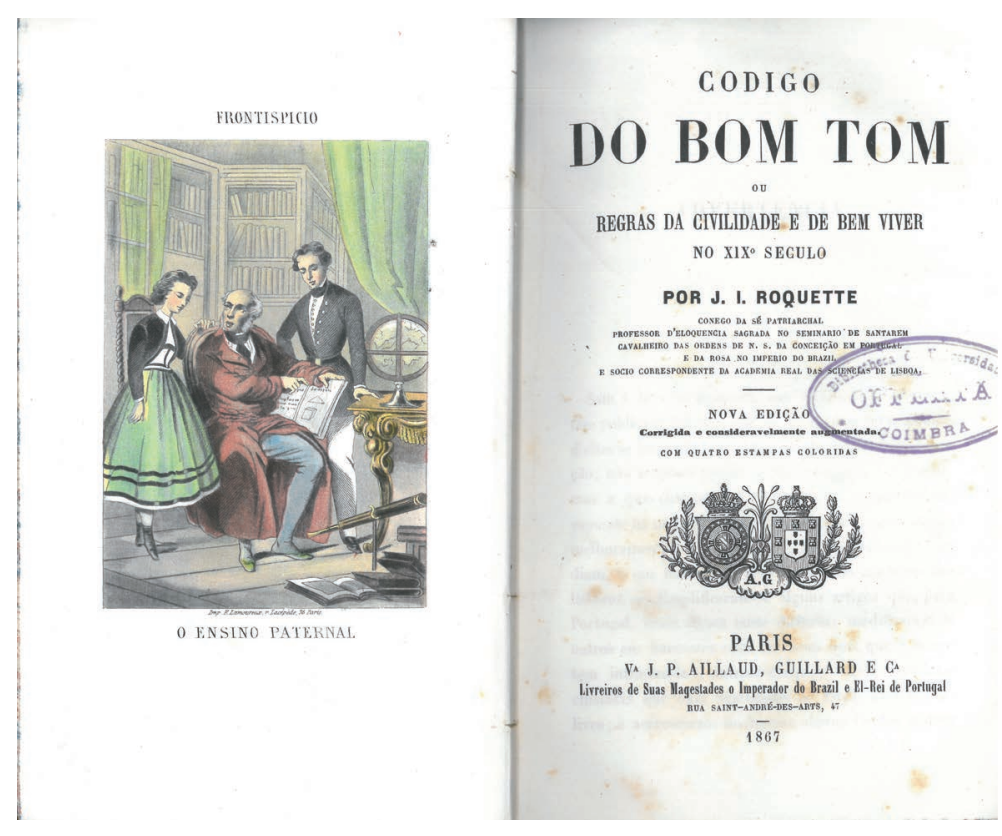

De entre a literatura normativa, convém, ainda, salientar tratados de etiqueta e/ou de educação doméstica que, para além de transmitirem modelos de comportamento e regras de conduta de acordo com a pauta de valores burgueses, à semelhança do aprendizado fornecido pelos manuais de civilidade, difundiam princípios de organização e do governo do lar. Dirigidos 
prioritariamente ao sexo feminino, em particular às donas de casa que aliam "a administração do lar às funções de uma dama da sociedade" (Vaquinhas, Guimarães, 2011: 203-220), a sua divulgação coincide com a importância atribuída à mulher, pela ideologia burguesa, no quadro da família. As obras da Condessa de Gencé (Tratado de Civilidade e de etiqueta), de Emília de Sousa Costa (Na sociedade e na família. Regras de convivência - Obrigações sociais - Usos mundanos - Notas íntimas, cat. n. ${ }^{\circ}$ 97), de Virgínia de Castro e Almeida (Como devo governar a minha casa, cat. n. ${ }^{\circ}$ 96) ou de Paulo Combes (O Livro da Dona de Casa) são alguns exemplos representativos desse género literário, bem acolhido pelo público, e a que não foi alheio o recurso a uma linguagem simples, despretensiosa e pedagógica.

A produção editorial deste tipo de obras aumentou significativamente nas primeiras décadas do século xx, acompanhando o florescimento da imprensa periódica feminina ou das páginas femininas dos jornais e de revistas que se convertem no veículo ideal para a difusão dos saberes adequados ao "governo do lar". Ajudou a consolidar esse género específico, a reconfiguração das ocupações da dona de casa, por motivo da redução do número de criados por agregado familiar, em consequência das dificuldades económicas provocadas pela I Grande Guerra. Por via deste tipo de obras, de claros intuitos propedêuticos e instrumentais, a vida quotidiana transformava-se em matéria de aprendizagem, tendo como prioridade capacitar a dona de casa para exercer as funções domésticas de maneira moderna, pela incorporação de técnicas de administração racional do lar e dos preceitos científicos da higiene.

De entre as matérias abordadas pelos manuais de civilidade, as "maneiras à mesa" figuram em lugar destacado, sendo objeto de recomendações muito precisas, desde a forma correta de usar os utensílios de mesa (talheres, guardanapos, palitos, pousa-facas...), de cortar a carne, passando pelo modo de fazer saúdes, comer fruta de caroço, entre outros aspetos. O esforço em demarcar fronteiras entre a "gente sem qualidade" e a "sociedade de bom tom" permite identificar os comportamentos reprováveis a evitar, como "engolir com precipitação", "assoprar a sopa", "mascar de forma que se ouça d'uma ponta da mesa à outra", entre outros “pecados imperdoáveis" do léxico da etiqueta (Cascão, 2011: 71-76). As relações com os serviçais, a convivência à mesa, os convites, a organização de jantares de aparato e de banquetes e o "modo de por a mesa" são matérias que obedecem igualmente às regras e aos formalismos propostos pelos manuais.

Já os tratados que cruzam a civilidade com princípios de economia doméstica tendem a associar às recomendações presentes nos manuais de civilidade, conselhos práticos e utilitários, detendo-se, entre outros aspetos, na disposição da sala de jantar, no tipo de serviço adequado a cada refeição, na sequência dos pratos em jantares de cerimónia, no traje a usar, nos menus mais convenientes ou na distribuição dos lugares à mesa. Os jantares "são sempre pretexto de ostentação", por via da iluminação, da roupa de mesa, do serviço de copa, da baixela, entre outros aspetos mais ou menos refinados, consonantes com o nível e a carteira dos anfitriões. Como esclarece Beatriz Nazareth, “o que é l...l d'uma elegância suprema, d'um luxo indispensável, é a alvura imaculada da toalha, a limpidez deslumbrante dos cristais e de todos os utensílios que servem para comer" (Nazareth, 1908: 68).

A multiplicação das formas de sociabilidade burguesas, sobretudo a partir da segunda metade do século Xix, fará inflacionar as situações mundanas, igualmente sujeitas ao cerimonial rigoroso da encenação dos quotidianos burgueses. “Tudo pode servir de pretexto para uma alegre refeição", sentencia a Condessa de Gencé no seu Tratado de Civilidade e de Etiqueta antes de se debruçar, com minúcia, nos aspetos práticos de lanches, de refeições campestres, de jantares de gala e de meia-gala, de soirées, entre outras ocasiões de convivência social (Gencé, 1935: 107).

Vetores de sistemas de valores, a literatura normativa ajudou a consolidar códigos morais e sociais. Ao pretender-se a auto-regulação dos comportamentos, a racionalização das condutas por meio da interiorização de normas, visava-se controlar todas as esferas da vida. Local de socialização por excelência, também a mesa não escapou a "minuciosas leis", a "praxes” e a regras... 
Almeida, D. Virgínia de Castro e (1906), Como devo governar a minha casa, Modificação e adaptação do livro italiano de Giulia Ferraris Tamburini. Lisboa: Livraria Classica Editora - A. M. Teixeira \& C. T.

Baronesa X (1937), Breviário das Donas de Casa (Livro indispensavel em todos os lares). Lisboa: Soc. Nacional de Tipografia.

Carvalho, Maria Amalia Vaz de (1909), A arte de viver em sociedade, $4^{\mathrm{a}}$ edição. Lisboa: Parceria Antonio Maria Pereira.

Codigo de Civilidade e Costumes do bom-tom seguido do Codigo Heraldico (1894). Lisboa: Henrique Zeferino - Livraria Editora.

Combes, Paulo (1934), O Livro da Dona de Casa, Tradução portuguesa, 4. ${ }^{a}$ edição, Porto, Editora: Educação Nacional.

Costa, Emília de Sousa (1925), Na sociedade e na família. Regras de convivência - Obrigações sociais - Usos mundanos - Notas íntimas. Lisboa: Livraria Clássica Editora de A. M. Teixeira \& C. ${ }^{a}$ (Filhos).

Gencé, Condessa de (1935), Tratado de civilidade e de etiqueta, 10. a edição actualizada, Lisboa, Livraria Editora Guimarães \& C. ${ }^{a}$

Nazareth, Beatriz (1908), Manual de Civilidade e Etiqueta. Regras indispensáveis para se frequentar a boa sociedade, 8. a edição Revista e notavelmente augmentada com muitos artigos novos sobre as praxes da etiqueta moderna. Lisboa: Editor - Arnaldo Bordalo.

Prevost, Ms. (1788), Elementos da civilidade e da decência que se practica entre a gente de bem, composta na língua franceza por Ms. PREVOST. Traduzidos na língua portuguesa por Jozé Vicente Rodrigues, natural, e morador da cidade do Porto. Lisboa: Na offic. de Antonio Gomes.

Roquette, J. L. (1850), Codigo do bom tom ou regras da civilidade e de bem viver no XIX ${ }^{o}$ século. $3 .^{\mathrm{a}}$ edição consideravelmente augmentada e corrigida. Pariz: V ${ }^{a}$ J.-P. Aillaud, Moulon \& C. ${ }^{a}$
Cascão, Rui (2011), “À volta da mesa: sociabilidade e gastronomia”, in História da Vida Privada em Portugal, dir. José Mattoso, vol. 3. A Época Contemporânea. Coord. Irene Vaquinhas. Lisboa: Círculo de Leitores, 56-91.

Rasteiro, Natércia Maria Carvalho (2010), Sociabilidades gastronómicas no Portugal Contemporâneo: práticas, modelos e espaços: sociabilidades burguesas encenadas no espaço privado. Coimbra. Faculdade de Letras da Universidade de Coimbra (Dissertação de Mestrado).

Santana, Flavio Carreiro de (2014), Majestosa Educação. Família e civilidade no segundo reinado do Brasil (1840-1889). Coimbra: Faculdade de Letras da Universidade de Coimbra (Tese de Doutoramento).

Santos, Maria de Lourdes Lima dos (1983), Para uma sociologia da cultura burguesa em Portugal no século XIX. Lisboa: Editorial Presença / ICS.

Terra, Ana Lúcia Silva (2000), Cortesia e mundanidade. Manuais de civilidade em Portugal nos séculos XVII e XVIII. Coimbra: Faculdade de Letras da Universidade de Coimbra (Dissertação de Mestrado).

Vaquinhas, Irene; Guimarães, Maria Alice Pinto (2011), “Economia doméstica e governo do lar. Os saberes domésticos e as funções da dona de casa", in História da Vida Privada em Portugal, dir. José Mattoso, vol. 3. A Época Contemporânea. Coord. Irene Vaquinhas. Lisboa: Círculo de Leitores, 194-221.

Vaquinhas, Irene Maria; Cascão, Rui (1993), “Evolução da sociedade em Portugal: a lenta e complexa afirmação de uma civilização burguesa”, in História de Portugal. dir. de José Mattoso, v vol. - O Liberalismo (1807-1890). Lisboa: Círculo de Leitores, 441-457. 